RODRIGUES, R.D. et al. Demodicose canina: relato de caso. PUBVET, Londrina, V. 6, N. 7, Ed. 194, Art. 1304, 2012.

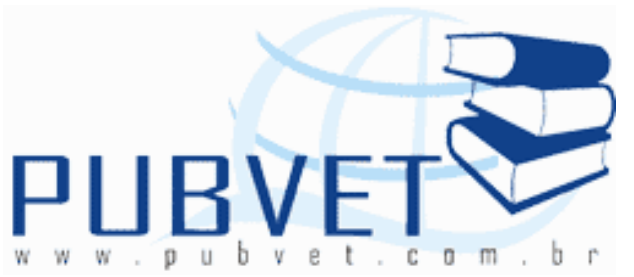

PUBVET, Publicações em Medicina Veterinária e Zootecnia.

\title{
Demodicose canina: relato de caso
}
Renata Dias Rodrigues ${ }^{1}$; Rafael Rocha de Souza2; Marcus Vinícius Alves da Silva ${ }^{1}$; Juliana Capello Toledo ${ }^{1}$.

${ }^{1}$ Graduandos em Medicina Veterinária. Universidade Federal de Uberlândia, MG.

2 Residente de Patologia Clínica Veterinária. Universidade Federal de Uberlândia, MG.

\section{Resumo}

A demodicose canina é uma das dermatopatias mais comumente encontradas na clínica veterinária. São declarados dois tipos de Demodicose a localizada (DL) e a Demodicose Generalizada (DG), sendo primeira com lesões típicas podendo ser descritas como manchas eritematosas e alopécicas na cabeça e/ou membros torácicos. Pode haver prurido e descamação fina, o curso é benigno e a maioria dos casos resolve-se espontaneamente. Em relação a Demodicose Generalizada (DG) esta é a forma mais grave da doença, e se apresenta como uma dermatite crônica com liquenificação, descamação, formação de crostas, hiperpigmentação, piodermatite severa e alopecia, cobrindo grandes áreas do corpo, frequentemente envolve infecções bacterianas secundárias. O tratamento deve ser global, não focar somente nos ácaros, mas também por vezes faz-se necessário o uso de antibióticos, optar por ração de boa qualidade, banhos semanais, melhorar a qualidade de vida 
RODRIGUES, R.D. et al. Demodicose canina: relato de caso. PUBVET, Londrina, V. 6, N. 7, Ed. 194, Art. 1304, 2012.

geral do animal. O proprietário deve ser alertado sempre em relação ao tempo de tratamento que é longo, são necessárias visitas ao veterinário quinzenalmente, e que pode ocorrer recidivas.

Palavras-chave: Cão. Demodex canis. Dermatopatias.

\title{
Canine demodicosis: a case report
}

\begin{abstract}
The canine demodicosis is one of the most common skin diseases encountered in veterinary practice. Are declared the two types of Localized Demodicosis (LD) and Generalized Demodicosis (GD), with typical lesions being first can be described as erythematous and alopecic patches on the head and / or forelimbs. There may be itching and flaking fine, the course is benign and most cases resolve spontaneously. For Generalized demodicosis (GD) this is the most severe form of the disease, and presents as a chronic dermatitis with lichenification, scaling, crusting, hyperpigmentation, pyoderma and severe alopecia, covering large areas of the body, often involves bacterial infections secondary. Treatment should be global, not focusing only on mites, but sometimes it is necessary to use antibiotics, choose to feed good quality, weekly baths to improve the overall quality of life of the animal. The owner must be alerted when compared to treatment time is long, are necessary visits to the vet every two weeks, and it can occur relapses.
\end{abstract}

Keywords: Dog. Demodex canis. Skin Diseases

\section{INTRODUÇÃO}

O Demodex canis faz parte da microbiota normal da pele canina, estando presente em pequeno número na maioria dos cães saudáveis, é uma dermatopatia parasitária inflamatória (SCOTT; MILLER; GRIFFIN, 1996; CONTE, 2008). Seu processo patológico desenvolve-se quando o número de ácaros excede o tolerado pelo sistema imunológico (RHODES, 2008). Fatores 
RODRIGUES, R.D. et al. Demodicose canina: relato de caso. PUBVET, Londrina, V. 6, N. 7, Ed. 194, Art. 1304, 2012.

como nutrição inadequada, estresse, endoparasitoses, enfermidades debilitantes, imunossupressão medicamentosa e as alterações endócrinas femininas durante o ciclo estral também são listados como contribuintes para o surgimento das lesões (BARRAGRY, 1994; NAYAK et al., 1997; MUELLER; BETTENAY, 1999; SCOTT; MILLER; GRIFFIN, 2001). O D.canis não é considerado contagioso, exceto para filhotes recém-nascidos em contato com a mãe portadora do acaro, durante os três primeiros dias de amamentação (GUERETZ, 2005).

De acordo com a literatura são declarados dois tipos de demodicose a localizada (DL) e a Demodicose Generalizada (DG), sendo primeira com lesões típicas podendo ser descritas como manchas eritematosas e alopécicas na cabeça e/ou membros torácicos. Pode haver prurido e descamação fina (SCOTT; MILLER; GRIFFIN, 2001), o curso é benigno e a maioria dos casos resolve-se espontaneamente. Em relação à Demodicose Generalizada (DG) esta é a forma mais grave da doença, e se apresenta como uma dermatite crônica com liquenificação, descamação, formação de crostas, hiperpigmentação, piodermatite severa e alopecia, cobrindo grandes áreas do corpo, mas o estabelecimento dessa patologia é rara em adultos e frequentemente envolve infecções bacterianas secundárias (PARADIS, 1999; MUELLER, 2004). A bactéria Staphylococus intermedius, gram-positiva, está envolvida em aproximadamente $90 \%$ dos casos (HERNI et al., 2006).

Para a realização do diagnóstico de demodicose, utiliza-se raspado de pele profundo, onde o resultado positivo é dado quando há demonstração aumentada de formas adultas do ácaro ou por relação aumentada de formas imaturas (ovos, larvas e ninfas) em relação aos adultos. No exame histopatológico as amostras de biópsia cutânea demonstram os folículos contendo ácaros e debris ceratinosos e perifoliculite inflamatória, foliculite ou furunculose supurativa (SCOTT et al., 1996).

As lesões microscópicas da demodicose generalizada podem variar em função da presença e da extensão da infecção bacteriana secundária e da geração de piodermite profunda. Tipicamente, o folículo piloso é ocupado por grande 
RODRIGUES, R.D. et al. Demodicose canina: relato de caso. PUBVET, Londrina, V. 6, N. 7, Ed. 194, Art. 1304, 2012.

número de ácaros em todos os níveis (YAGER e SCOTT, 1992). Lesões crônicas severas consistem de fibrose dérmica com obliteração de estruturas anexas (HARGIS e GINN, 2007).

\section{RELATO DE CASO}

A história clínica e a anamnese foram realizadas no dia 22 de setembro quando este animal compareceu para consulta, trata-se uma cadela (Pretinha), 3 anos, sem raça definida, pesando $6,750 \mathrm{Kg}$, acompanhada de sua proprietária. As queixas principais da proprietária eram: prurido intenso, pele seca e extensas áreas de alopecia, tratamentos realizados para sarna sem sucesso. Proprietária relatou que o animal apresentava este prurido havia certo tempo, mas os sinais aumentaram nas ultimas duas semanas. Foi questionado se havia outro animal e a resposta foi afirmativa. Quando indagada se o outro animal também se coçava, proprietária negou. Também foi observado a presença de pústulas, indicando possível infecção secundária.

Durante o exame físico o animal apresentou grau leve de desidratação, mucosas oral e conjuntiva se encontravam normocoradas. No exame objetivo a aferição da temperatura foi igual a $38,9{ }^{\circ} \mathrm{C}$, freqüência cardíaca de 134 batimentos por minutos e rítmicos. Encontrava-se alerta e responsivo ao meio. Diagnóstico provisório foi indicativo de demodicose, confirmado posteriormente através de exames complementares (hemograma e raspado de pele). Assim sendo, perante todo e qualquer animal apresentando demodicose em idade adulta, é recomendada a realização de exames laboratoriais, que incluam pelo menos um hemograma, um perfil bioquímico e porventura provas endócrinas específicas que avaliem a função tireóidea e/ou adrenal, de forma a detectar eventuais doenças associadas tais como hipotiroidismo ou hiperadrenocorticismo (SCOTT et al., 2001). O raspado de pele (RP) profundo é considerada o exame de eleição para o diagnóstico da demodicose. Com uma sensibilidade de 100\% (BENSIGNOR, 2003; SARIDOMICHELAKIS, KOUTINAS, FARMAKI, LEONTIDES; KASABALIS, 2007), quando corretamente realizada e 
RODRIGUES, R.D. et al. Demodicose canina: relato de caso. PUBVET, Londrina, V. 6, N. 7, Ed. 194, Art. 1304, 2012.

interpretada, é a forma mais fácil de estabelecer um diagnóstico final. O protocolo terapêutico adotado foi a prescrição do uso de Mectimac $\Re 3 \mathrm{mg}$ (endectocida de uso oral, à base de ivermectina, indicado no tratamento das sarnas e verminoses dos cães) a posologia foi de 1 comprimido, a cada 24 horas, durante 15 dias. Estudos realizados por Karakurum et al. (2007), optaram por utilizar ivermectina em comprimidos, no qual avaliou-se a eficácia de um protocolo diário na posologia de $600 \mu \mathrm{g} / \mathrm{kg} / \mathrm{uma}$ vez ao dia, para o tratamento de 16 animais com demodicose. Os resultados foram bastante satisfatórios, tendo obtido $82,25 \%$ de eficácia no tratamento dos animais afetados. Também foi prescrito o uso do Advocate $\AA$ (proteção completa contra parasitas externos e internos) a cada 30 dias. Em ensaios clínicos mais recentes demonstraram que este produto revela-se também eficaz e seguro no tratamento da demodicose canina (HEINE, KRIEGER, DUMONT; HELLMAN, 2005; MUELLER, MEYER \& BENSIGNOR, 2008). Concluíram que, devido à facilidade de aplicação, segurança e eficácia clinicamente comprovada, este produto é uma interessante alternativa terapêutica, especialmente indicado para animais que manifestem um quadro clínico ligeiro desta doença (MUELLER et al., 2008). Bactrin $F \circledast$ (quimioterápico bacteriostático (sulfonamida) antibacteriano (amplo espectro) e protozoostático), $1 \mathrm{~mL}$, a cada 12 horas durante 10 dias, banhos uma vez por semana com sabonete Protex e melhora na qualidade da ração. Após 15 dias de tratamento o animal retornou ao hospital, no qual avaliou-se uma melhora considerável do caso, apresentando melhor atitude e aparência, exibindo crescimento piloso e, uma remissão parcial dos sinais clínicos, porém algumas áreas alopecia, presença de crostas e eritema ainda eram visíveis. Foi solicitado à proprietária que continuasse com o tratamento, mas infelizmente, não foi possível avaliar com precisão a evolução da sua resposta à terapêutica pois este animal não regressou para a segundo retorno e monitorização terapêutica. É importante ressaltar que embora o período de tratamento seja geralmente bastante prolongado, por precaução o tratamento deverá ser mantido até que se obtenha duas séries de raspagens negativas com um mês de intervalo, qualquer que seja o acaricida 
RODRIGUES, R.D. et al. Demodicose canina: relato de caso. PUBVET, Londrina, V. 6, N. 7, Ed. 194, Art. 1304, 2012.

utilizado (HUBERT et al., 2003). Ainda assim, alguns autores defendem que, ultrapassado esse período suplementar, de forma a diminuir a probabilidade de uma recidiva, o tratamento deverá ser ainda prolongado por mais um mês (SCOTT et al., 2001).

\section{CONSIDERAÇÕES FINAIS}

A demodicose canina ainda é uma das dermatopatias comumente encontradas na clínica veterinária, apesar de seu fácil diagnóstico laboratorial, e da existência de uma forma localizada, que em geral não precisa ser tratada, existe também a forma generalizada, que pode comprometer severamente o estado físico do animal.

O tratamento deve ser global, não focar somente nos ácaros, mas também por vezes faz-se necessário o uso de antibióticos, optar por ração de boa qualidade, banhos semanais, melhorar a qualidade de vida geral do animal.

O proprietário deve ser alertado sempre em relação ao tempo de tratamento que é longo, são necessárias visitas ao veterinário quinzenalmente, e que pode ocorrer recidivas.

\section{REFERÊNCIAS}

BARRAGRY, T. B. Demodetic mange (Demodicosis). In: BARRAGRY, T. B. Veterinary drug therapy. Philadelphia: Lea \& Febiger, p. 385-399, 1994.

BENSIGNOR, E. Comparaison de trois techniques diagnostiques de démodécie à Demodex canis chez le chien. Pratique Médicale et Chirurgicale de I'animal de Compagnie, v. 38, n.2, p. 167-171, 2003.

CONTE, A.P. Demodicose Canina Generalizada: Relato de Caso. Universidade Castelo Branco de Pós Graduação em Medicina Veterinária - Clínica Médica e Cirúrgia de Pequenos Animais. Braço do Norte, 2008.

GUERETZ, J.S. Prevalência pontual de Demodex Canis e de Demodicose em parcela da população canina, na cidade Guarapuava - Paraná. 2005. Dissertação (Mestrado em Patologia Animal) - Pós Graduação em Ciências Veterinárias (Ciências Agrárias), Universidade Federal do Paraná. 
HARGIS, A. M.; GINN, P. E. The integument. In: McGAVIN, M. D.; ZACCHARY, J. F. Pathologic basis of Veterinary disease. 4 ed. Sanit Louis: Mosby, p. 1107- 1261, 2007.

HEINE, J.; KRIEGER, K.; DUMONT, P. \& HELLMAN, K. Evaluation of the efficacy and safety of imidocloprid $10 \%$ plus moxidectin $2,5 \%$ spot-on in the treatment of generalizes demodicosis in dogs: results of a European field study. Parasitology Research, 97, 89-96, 2005.

HERNI, J. A.; BOUCHER, J. F.; SKOGERBOE, T. L.; TARNACKI, S.; GAJEWSKI, K. D.; LINDEMAN, C. J. Comparison of efficacy of cefpodoxime proxetil and cephalexin in treating bacterial pyoderma in dogs. International Journal of Applied Research in Veterinary Medicine, v.4, p. 85-93, 2006.

HUBERT, T.; GUAGUÈRE, E. \& MULLER, A. Comment concevoir un traitement contre la demodécie du chien. Pratique médicale et chirurgique de I'animal de compagnie, v.38, p. 23-28., 2003.

KARAKURUM, M. C.; URAL, K.; CINGI, C. C.; GUZEL, M.; HAYDARDEDEOGLU, A. E. \& BORKU, M.K. Evaluation of ivermectin tablets in the treatment of generalized canine demodicosis. Revue de Médecine Vétérinaire, v.158, n.7, p. 380-383, 2007.

MUELLER, R. S.; HASTIE, K.; BETTENAY, S. V. Daily oral ivermectin for the treatment of generalized demodicosis in 23 dogs. Australian Veterinary Practitioner, v. 29, p. 132-136, 1999.

MUELLER, R.; MEYER, D. \& BENSIGNOR, E. Treatment of canine generalized demodicosis with a "spot-on" formulation containing $10 \%$ moxidectin and $2,5 \%$ imidacloprid (Advocate ${ }^{\circledR}$, Bayer). Veterinary Dermatology, v.19, (s1), p.12-13, 2008.

MUELLER, RALF S. Treatment protocols for demodicosis: an evidence-based review. Veterinary Dermatology, v. 15, 75-89, 2004.

NAYAK, D. C.;TRIPATHY, S.B.; DEY, P.C.; RAY,S.K.; MOHANTY, D.N.; PARIDA, G.S.; BISWAL, M.S. Prevalence of canine demodicosis in Orissa (India). Veterinary Parasitology, v. 73, n.34, p. 347-352, 1997.

PARADIS, M. New approaches to the treatment of canine demodicosis. Vet. Clin. North Am.: Small Animal Practice, v.29, p.1425-1436, 1999.

SARIDOMICHELAKIS, M.; KOUTINAS, A.; FARMAKI, R.; LEONTIDES, L. \& KASABALIS, D. Relative sensitivity of hair pluckings and exsudate microscopy for the diagnosis of canine demodicosis. Veterinary Dermatology, v.18, n.2, p. 138-141, 2007.

SCOTT, D.W.; MILLER, W.H.; GRIFFIN, C.E. Muller \& Kirk. Dermatologia de Pequenos Animais. 5.ed. Rio de Janeiro: Interlivros, 1996.

SCOTT, D. W.; MILLER, W. H.; GRIFFIN, C. E. Doenças parasitárias da pele. In: Muller e Kirk Dermatologia de Pequenos Animais. 5.ed. Interlivros Edições Ltda, Rio de Janeiro, $1996,1130 \mathrm{p}$.

SCOTT, D.; MILLER, W. \& GRIFFIN, C. Muller \& Kirk's: Small Animal Dermatology. 6.ed. Philadelphia: Saunders, 2001. 
RHODES, K.H. Demodicose. In:TILLEY, L.P.; SMITH JR., F.W.K. Consulta Veterinária em 5 minutos: Espécie canina e felina. 3.ed. Barueri: Manole, 2008.

YAGER, J.A.; SCOTT, D. W. The skin and appendages. In: JUBB, K. V. F.; KENNEDY, P.C.; PALME, N. Pathology of domestic animals. San Diego: Academic Press. v.1, p.531-737, 1992. 